\title{
Bruksizmde Botulinum Toksini Etkinliğinin Değerlendirilmesi
}

\author{
Evaluation of Botulinum Toxin Effectiveness on Bruxism
}

\author{
Ozan KUDUBAN ${ }^{1}$, Selma DENKTAŞ KUDUBAN ${ }^{2}$ \\ ${ }^{1}$ Erzurum Bölge Eğitim Araştırma Hastanesi Kulak Burun Boğaz ve Baş Boyun Cerrahisi Kliniği, Erzurum \\ ${ }^{2}$ Op. Dr. Selma Denktaș Kuduban Estetik Plastik ve Rekonstrüktif Cerrahi Kliniği, Erzurum
}

\begin{abstract}
$\ddot{O ̈ z}$
Bruksizm, toplumda $\% 20$ oranında görülme sıklığı bildirilmiş olan çiğneme kaslarının nokturnal veya diurnal tekrarlayan aktivitesidir. Baş ağrısı, diş sıkma ve bunun sonucu olarak dişlerde yapısal bozukluklar, yaygın yüz ağrısı gibi şikayetlere neden olarak kişinin hayat kalitesini olumsuz etkileyen bir rahatsızlıktır. Tedavide birçok seçenek kullanılmıs olup özel bir algoritma tanımlanamamıştır. Dentalsplint kullanımından farmakolojik tedavilere kadar birçok seçenek literatürde yerini almış olmakla beraber bu tedavilerin uzun süre kullanım gerekliliği nedeniyle yarıda bırakılma oranları yüksek olabilmektedir. Bu çalışmamızda son yıllarda farklı hastalıklarda tercih edilmekte olan, ortalama yılda iki kez uygulamanın yeterli olduğuve bilinen güçlü bir bakteri toksiniolan Botulinum toksin

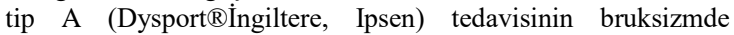
etkinliğini retrospektif olarak değerlendirmeyi amaçladık.
\end{abstract}

Anahtar Kelimeler: Baș Ağrısı, Botulinum Toksini, Bruksizm

\section{Giriş}

Bruksizm, dişlerin sıkılması veya gıcırdatılması ile karakterize çiğneme kaslarının nokturnal veya diurnal tekrarlayan aktivitesidir. Erişkin popülasyonda yaklaşık \%8-10 oranında görülmektedir (1). Baş ağrısı, uyku bozukluğu, temporomandibuler eklem bozukluğu, dişlerin kırılmasına kadar gidebilen yapısal bozukluklara ve yaygın orofasiyal ağriya neden olabilen bir rahatsızlıktır (2). Bruksizm tanısı için anamnez en önemli basamaktır. Hastanın dişlerini gıcırdatması veya sıkması sorgulanmalıdır (3). Anamnez derinleştirilerek diğer şikayetlerin varlığını da sorgulamak kaydı ile tanı güçlendirilir.

Bruksizm etiyolojik neden varlığı bulunma durumuna göreprimer ve sekonder olarak sınıflandırılabilir. Sekonder bruksizmde; anksiyete ve stres gibi psikolojik, serebralpalsi gibi nörolojik hastalıklar, bazı psikiyatri ve kardiyoloji ilaçların kullanımı başlıca nedenler arasında sayılabilir(4,5); tedavi etkene yönelik olmaktadır. Primer bruksizm tedavisinde geleneksel tedavilerin yanı sira son yıllarda artan sıklıkta botulinum toksin tip A(BT-A) kullanılmaktadır (6). BT-Aanaerob bir bakteri olan Clostridiumbotulinum tarafindan yapılan bir

$\begin{array}{ll} & \text { ORCID No } \\ \text { Ozan KUDUBAN } & \text { 0000-0002-4046-4999 }\end{array}$

Selma DENKTAS KUDUBAN 0000-0002-4066-056X

$\begin{array}{ll}\text { Başvuru Tarihi / Received: } & 25.12 .2020 \\ \text { Kabul Tarihi / Accepted : } & 24.07 .2021\end{array}$

Adres / Correspondence : $\quad$ Ozan KUDUBAN

Erzurum Bölge Eğitim Araştırma Hastanesi Kulak Burun Boğaz ve Baş Boyun Cerrahisi Kliniği, Erzurum

e-posta / e-mail

ozankuduban@gmail.com

\begin{abstract}
Bruxism is the nocturnal or diurnal repetitive activity of the masticatory muscles, which has been reported to be seen at an incidence of $20 \%$ in the population. It is a condition that negatively affects the quality of life by causing complaints such as headache, tooth clenching and, as a result, structural disorders in the teeth and wide facial pain. Many options have been used in treatment, but a special algorithm has not been defined yet. Although many options from the use of dental splint to pharmacological treatments have taken place in the literature, the rate of discontinuation of these treatments may be high due to the long-term use of these treatments. In this study, we aimed to evaluate retrospectively the efficacy of Botulinum toxin type A (Dysport ${ }^{\circledR}$ England, Ipsen), which is a wellknown strong bacterial toxin and sufficient to apply twice a year on average for the treatment of bruxism.
\end{abstract}

Keywords: Headache, Botulinum Toxin, Bruxism

proteindir. Paralitik etkisi ile nöromuskuler kavşakta asetilkolin salınımını inhibe ederek kaslarda geri dönüşümlü denervasyon atrofisine neden olur. $\mathrm{Bu}$ mekanizmadan yola çıkılarak uygulanmaya başlayan BT-A'nın fasiyal plastik cerrahide bruksizmi de kapsayan birçok endikasyonda gün geçtikçe kullanımı artmaktadır.

$\mathrm{Bu}$ çalışmamızda diş sıkma ve baş ağrısı şikayetleri ile başvuran ve yapılan değerlendirme sonucunda bruksizm tanisi konulan hastalara tedavide tercih ettiğimiz BT-A etkinliğini retrospektif olarak değerlendirmeyi amaçladık.

\section{Gereç ve Yöntem}

Çalışmaya 2018 ile 2020 yılları arasında bruksizm tanisı konulan toplam 31 hasta dahil edildi.Tedavisi gerçekleştirilen hastalardan işlem sonrasi kontrol muayene randevusuna gelmeyen toplam 4 hasta, şikayet ve sonuç şikayetlerini değerlendirmede objektif olamadığı düşünülen 1 hasta ile antidepresan ilaç kullanım öyküsü olan 1 hasta çalışmaya dahil edilmedi. Antidepresan ilaç kullanım öyküsü olan hastada hangi tedavinin etkili olduğu/olmadığı konusunda kesin bir hükümde bulunulamayacağ 1 için çalışma haricinde tutuldu. Hastalara gerekli bilgilendirme yapılıp onam formlar1 doldurulduktan sonra lidokain krem ile uyuşturularak 20 dakika beklendi. $2-8^{\circ} \mathrm{C}$ aralığında buzdolabında saklanan BT-Afrajil bir toksin olduğu için sulandırma işlemi esnasında salin flakon içine nazikçe enjekte edildi. Baloncuklanma toksinin yüzey denatürasyonuna ve bu nedenle de etkisiz kalacağına neden olabileceği için (7) sulandırıldıktan sonra çalkalanmadı. Botulinum 
toksin A (Dysport $\AA$ İngiltere, Ipsen)için speywood ünitesi (s.U) birimi kullanıldı. Yapılan çalışmalarda etkinlik açısından 1 ünite yaklaşık olarak2,5 speywood ünitesine eşdeğer görülmüştür.

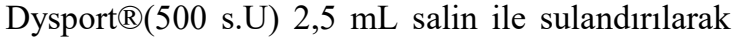
200 s.U/mL olan son konsantrasyonuna ulaşır.BT-A hazır hale getirildikten sonra sağ masseter kası için Stenon kanalı ve fasiyal sinir trasesine dikkat edilerek 3 noktaya 5'er ünite olmak üzere toplam 15 s.U BT-A(Dysport $\left.{ }^{\circledR}\right)$ kas içine enjekte edildi (8) (Resim 1). Daha sonra aynı işlem sol masseter kasa da uyguland. Hiçbir hastaya kontrol muayenelerinde ilave doza gerek duyulmadı.

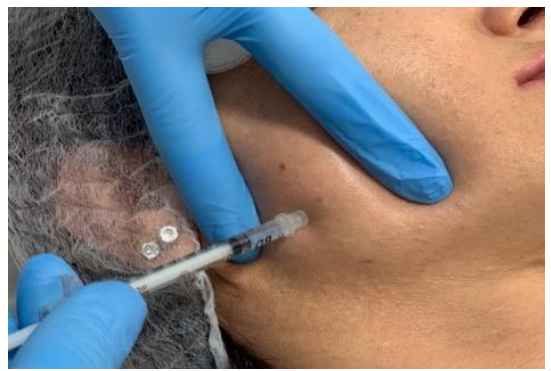

Resim 1. Masseter kası içine Botulinum Toksin enjeksiyonu

Çalışmamızın değerlendirilmesinde sayısal olarak ölçülemeyen değerleri sayısal hale çevirmek amacıyla Vizüel Analog Skala (VAS) (9) kullanıldı. Hastalara skorlama için 0'dan 10'a kadar; hiç ağr1 olmaması ve diş sıkma olmaması 0, hayatta hissedilen en şiddetli ağrı ve dişlere zarar verecek düzeyde diș sıkma 10, orta derece ağrı ve diş sıkmanın 5 puan olduğu açıklandı. Bu açıklamaların 1şığında hastalardan istirahat ve fonksiyon halindeki ağrıları ve diş sıkma seviyeleri sorgulanarak10 cm'lik çizgi üzerinde işaretlendi. Aynı değerlendirme tüm hastalara kontrol muayenelerinde de yaptırıldı.

İstatistiksel analizler için NCSS (NumberCruncher Statistical System) 2007 (Kaysville, Utah, USA) programı kullanıldı. Çalışma verileri değerlendirilirken tanımlayıcı istatistiksel metotların (Ortalama, Standart Sapma, Medyan, Frekans, Oran, Minimum, Maksimum) yanı sıra verilerin dağılımı Kolmogorov-Smirnov Testi ile değerlendirildi. Dönemsel verilerin karşılaştırılmasında Wilcoxon testi kullanıldı. Anlamlılık $\mathrm{p}<0.05$ düzeyinde değerlendirildi.

Çalışmamıza Erzurum Bölge Eğitim Araştırma Hastanesi Klinik Araştırmalar Etik Kurulu tarafindan 02.11.2020 tarih ve 2020/20-196 sayılı kararı ile etik kurul onayı verilmiştir. Çalışmamız Helsinki Deklarasyonu'na (World Medical Association Declaration of Helsinki http://www.wma.net/en/30/publications/10policies/ b3/index.html) göre yapılmıştır.

\section{Bulgular}

Çalıșmaya dahil edilen 31 hastanın tümü kadın cinsiyetten oluşmakta, yaşları 23 ile 50 arasında değişmekte olup yaş ortalamaları $33.55 \pm 6.55$ idi. İşlem tarihi ile kontrol tarihi arası günü 8 ile 72 arasında değişmekte olup ortalama $17.32 \pm 11.27$ olduğu tespit edildi (Tablo 1). Hastaların 26'sında sigara alışkanlığı yok iken, 5 hasta sigara kullanım alışkanlığına sahip hastalardı. (Tablo 2). İşlem sonrası baş ağrısı VAS skorunun ișlem öncesi VAS skoruna göre düşük olması istatistiksel olarak anlamlı bulundu( $\mathrm{p}=0.001 ; \mathrm{p}<0.01)$. İşlem sonrası diş sıkma VAS skorunun işlem öncesi VAS skoruna göre düşük olması istatistiksel olarak anlamlı bulundu ( $\mathrm{p}=0.001 ; \mathrm{p}<0.01)$ (Tablo 3). Tedavisi yapılmış olan bir hastamızın işlem öncesi ve işlem sonrası 15. gün fotoğrafları Resim 2'de görülmektedir.

Tablo 1. Ölçüm ortalamaları

\begin{tabular}{ccc}
\hline & Ort \pm Ss & $\begin{array}{c}\text { Median } \\
\text { (Minimum-Maximum) }\end{array}$ \\
\hline Yaş & $33.55 \pm 6.55$ & 34 \\
İşlem ile & $(23-50)$ \\
$\begin{array}{c}\text { kontrol arası } \\
\text { gün }\end{array}$ & $17.32 \pm 11.27$ & 15 \\
& & $(8-72)$ \\
\hline
\end{tabular}

Tablo 2. Sigara kullanımına göre hasta dağılımı

\begin{tabular}{ccc}
\hline & & $\mathbf{n}$ \\
Sigara Kullanımı & Hayır & 26 \\
& Evet & 5 \\
\hline
\end{tabular}

Tablo 3: Dönemlere göre VAS skorunun karşılaştırılması

\begin{tabular}{|c|c|c|c|c|}
\hline & & $\begin{array}{l}\text { İşlem } \\
\text { Öncesi }\end{array}$ & $\begin{array}{c}\text { İşlem } \\
\text { Sonrası }\end{array}$ & $\mathbf{p}$ \\
\hline $\begin{array}{c}\text { Baş Ağrısı } \\
\text { VAS Skoru }\end{array}$ & $\begin{array}{c}\text { Ort } \pm \text { Ss } \\
{[\text { Median }} \\
(\text { Mini-Max })]\end{array}$ & $\begin{array}{c}8.87 \pm 0.81 \\
{[9(7-10)]}\end{array}$ & $\begin{array}{c}3.06 \pm 1.03 \\
{[3(2-6)]}\end{array}$ & 0.001 \\
\hline $\begin{array}{c}\text { Diş Sıkma } \\
\text { VAS Skoru }\end{array}$ & $\begin{array}{c}\text { Ort } \pm \text { Ss } \\
{[\text { Median }} \\
\text { (Min-Max] }\end{array}$ & $\begin{array}{c}9.19 \pm 0.79 \\
{[9(7-10)]}\end{array}$ & $\begin{array}{c}2.81 \pm 0.87 \\
{[3(2-5)]}\end{array}$ & 0.001 \\
\hline
\end{tabular}

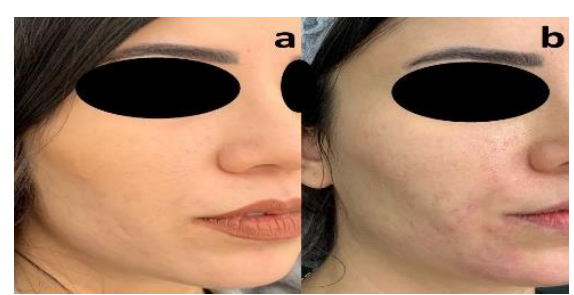

Resim 2. Tedavisi yapılmış olan bir hastamızın işlem öncesi ve işlem sonrası 15. gün fotoğrafları (a: İşlem öncesi; b: İşlemin 15. günü)

\section{Tartışma}

$\mathrm{Bu}$ çalışmada bilinen en güçlü bakteri toksini olan BT-A bruksizmde etkinliği değerlendirilmiştir. Bruksizm; baş ağrısı, diş sıkma ve buna bağlı kalıcı diş bozukluklarına, çene eklemi rahatsızlıklarına 
neden olur. $\mathrm{Bu}$ şikayetler kişinin hayat kalitesini olumsuz etkilerken klinisyenleri de tedavi seçenekleri için yoğun araştırmalara yöneltmektedir. Ancak hakkında gün geçtikçe daha fazla bilgi sahibi olmamıza rağmen bruksizm etiyolojisinin genellikle multifaktöryel olması tedavide hekimlerin karşılaştıkları en önemli güçlüktür (10). Sekonder bruksizmde tedavi önceliği etiyolojiye yönelik olmalidir.

Bruksizmde tedavi seçenekleri dental splint kullanımı, fizik tedavi, psikolojik tedavi ve farmakolojik tedavi olarak siralanabilir. Dental splintler özellikle temporomandibuler ekleme baskıyı azaltmak için diş hekimlerince başvurulan aparatlardır. Psikodavranışsal yöntemler ise gevşeme, "biofeedback" eğitim programları ve hipnoz ile tedaviyi kapsar. Biofeedback eğitimlerinin çiğneme kas aktivitesini azaltmada etkin bir yol olduğu tespit edilmiş, ancak yapılan takiplerde tedaviden sonra etkisinin kaybolduğu görülmüştür. Antidepresanlar ve analjezikler başta olmak üzere bruksizm tedavisinde reçete edilen çeşitli farmakoterapötik ajan vardır. Bunların uzun süreli kullanım gerekliliğinin getirdiği güçlükler ve istenmeyen birçok yan etkilerinin varlığı en önemli dezavantajlarıdır. Trisiklik antidepresanlar bunun için kullanılmış ve hastaların şikayetlerinde azalma gösterilmiştir (11).

BT-A terapötik amaçla ilk olarak 1970'li yıllarda şaşılık için tedavi fikrinden yola çıkılarak farelerde yapılan deneysel çalışmaların tamamlanmasının ardından 1980'li yılların başlarında hastalarda bu hastalığın tedavisinde kullanılmıştır (7). Daha sonra estetik ve kozmetik alanda da kullanılmaya başlayan BT-A endikasyon marjı gün geçtikçe genişlemiştir. Günümüzde lokalizasyonuna göre spastisite, myoklonus gibi nörolojik; strabismus, nistagmus gibi oftalmolojik hastalıklarda; akalazya ve zayıflama tedavileri ile bruksizmde kullanımı yaygın hale gelmiştir. BT-A maksillofasiyal uygulamalarda etkinliği yapılan çalışmalarda gösterilmiştir. Estetik fasiyal uygulamaların yanı sıra temporomandibuler eklem hastalıklarında, kas hipertrofileri ve spazmlarında, migrende, trigeminal nevraljide, serebralpalsi gibi nörolojik hastalıklara bağlı siyalorede ve hatta dental implant uygulamalarından sonra uygulamalarda başarılı sonuçlar alındığı birçok kez rapor edilmiştir (12-14).

Primer bruksizmdeki etkinlik sonuçlarımız literatürle uyumludur. Fernández-Núñez ve ark. yapmış oldukları derlemede 4 klinik randomize çalışma irdelenmiş ve tamamında BT-A kullanımı ile bruksizm semptomlarının belirgin düzelmeyle sonuçlandığını rapor etmişlerdir (15). Kumar ve ark. da çalıșmalarında bruksim için BT-A masseter kası kontraksiyonlarını azaltarak şikayetleri minimalize eden optimal bir tedavi seçeneği olduğunu belirtmişlerdir (16). Bununla birlikte temporomandibuler eklem bozukluğu olanlarda veya tek taraflı çiğneme alışkanlığı olan hastalarda kas diğer tarafa göre daha kuvvetli olabileceği için ek doz gerekebilir. Ancak fazla miktarda BT-A uygulamasının komplikasyon riskini artıracağ unutulmamalıdır (17). İlacın uygulama alanına bağlı olan yan etkileri ödem, eritem, ekimoz, konuşma güçlüğü olarak sıralanabilir; uygulama alanına bağlı olmayan yan etkileri ise generalize eritem, dispne, yutma güçlüğü ve anaflaksi olarak sıralanabilir. Yan etki için $100 \mathrm{U}$ doz ise kritik eşik olarak saptanmıştır (10).

Baş ağrısı olan bruksizm hastalarında yapılan çalışmalar temporal kas içine BT-A uygulamasının da şikayetin azaltılmasına katkıda bulunacağını bildirmişlerdir (15). Bizim uygulamalarımızda ise hastalarımızın olumlu geri dönüşleri sadece masseter kasa yaptığımız uygulamanın yeterli olduğu hatta ek doza bile gerek duyulmamakta; bu nedenletemporal kasa herhangi bir işlem yapılmamaktadır.

BT-Abilinen oldukça güçlü bir toksin olmasına karşın yan etkileri azdır (18). Gebelikte; laktasyon periyodu boyunca; toksin veya human albumine karşı aşırı duyarlılığı olanlarda; aminoglikozid, penisilamin, kinin, siklosporin ve kalsiyum kanal blokeri ilaçlarını kullanım esnasında; Myastenia Gravis, Eaton-Lambert gibi nöromuskuler hastalığ olan kişilerde kullanımı kontrendikedir (7). Çalışmamızda hiçbir hastada BT-A yan etkisi ile karşılaşılmaması; anamnezin dikkatli ve doğru alınmasının değerini gösteren önemli bir veridir. Gözden kaçırılmaması gereken en önemli konulardan biri ise BT-A klinik etki süresinin 3-6 ay kadar olması nedeniyle düzenli periyotlarda tedavinin tekrarlanacağı hastalara belirtilmeli, tekrarlayan enjeksiyonlarla etki süresinin daha da uzayabileceği açıklanmalıdır.

BT-A uygulamalarının etkinliğin başlayacağı 57. günden sonra kontrol muayenelerinin de yakın zamanda yapılması önerilmektedir (19). Çalışmamızda hastaların kontrol için başvurdukları günün median değeri 15 olarak tespit edildi. Hastalarımızın istenilen zaman aralığı içinde kontrol muayenesi için başvurmuş olmaları olumlu sonuçlar alma adına değerlidir.

Sigara kullanımı ile bruksizm ilişkisinin değerlendirildiği bir çalışmada ilacın doz stabilitesinin etkilenmediği gözlemlenmiştir (20). Çalışmamızda hastaların \%16.1'nde $(n=5)$ sigara kullanım alışkanlığı olduğu ancak içmeyenlere göre sonuçlarda anlamlı bir farklılık olmadığı sonucuna ulaşılmıştır. Bununla birlikte sigaranın hayat kalitesini düşürmek suretiyle birçok olumsuz duruma neden olduğu (21); bu şekilde debruksim için kolaylaştırıcı bir etken olabilir.

Sonuç olarak, BT-A bruksizmde etkili bir tedavi seçeneğidir. Dikkatli bir anamnez alındıktan sonra anatomiye hakim olunarak doğru noktalara ve uygun dozda işlemin yapılması güvenliği artıracak ve hastaların hayat kalitesinin artmasına katkıda bulunacak önemli kilit noktalardır. 
Etik Kurul Onayı: Erzurum Bölge Eğitim Araştırma Hastanesi Klinik Araştırmalar Etik Kurulu'ndan 02.11.2020 tarih ve 2020/20-196 kayit numarası ile etik kurul onayı alınmıştır.

\section{Kaynaklar}

1. Lobbezoo F, van der Zaag J, vanSelms MK, Hamburger HL, Naeije M. Principles for the management of bruxism. J Oral Rehabil. 2008;35(7):509-23.

2. Beddis $\mathrm{H}$, Pemberton M, Davies S. Sleepbruxism: an overviewforclinicians. BrDent J. 2018;225(6):497-501

3. Miloro M, Ghali GF, Larsen P, Waite P. Peterson's Principles of Oral and Maxillofacial Surgery. 2nd ed. Hamilton: B.C. Decker Inc; 2004.

4. Needham R, Davies SJ. Use of the Grindcare ${ }^{R}$ device in the management of nocturnal bruxism: a pilot study. $\mathrm{Br}$ Dent J. 2013;215(1):E1.

5. Erdoğ M, Arifağaoğlu Ö, Karabekmez D. Bruksizm teşhis ve tedavisi üzerine güncel yaklaşımlar: Derleme. Turk J Clin Lab. 2019; 10: 251-8.

6. Al-Wayli H. Treatment of chronic pain associated with nocturnal bruxism with botulinumtoxin. A prospective and randomized clinical study. J Clin Exp Dent. 2017;9(1):1127.

7. Baysal V, Yıldırım M. Botulinum Toksini ve Dermatolojide Kullanımı. TÜRKDERM. 2002; 36: 92-6.

8. Casale R, Tugnoli V. Botulinumtoxinforpain. Drugs R D. 2008;9(1):11-27.

9. Paul-Dauphin A, Guillemin F, VirionJM, ve ark. Biasand Precision in Visual Analogue Scales: A Randomized Controlled Trial. Am J Epidemiol.1999; 150(10): 1117-27.
10. Tinastepe N, Küçük BB, Oral K. Botulinum toxin for the treatment of bruxism. Cranio. 2015;33(4):291-8.

11. Bulut AC, Atsü S. Bruksizm Tanı ve Tedavisinde Güncel Yaklaşımlar. Kırıkkale Üni Tıp Fak Derg. 2012;14:20-5.

12. Rao LB, Sangur R, Pradeep S. Application of Botulinum toxin type A: An arsenal in dentistry. Indian J Dent Res. 2011;22:440-5.

13. Fuster Torres MA, Berini Aytés L, GayEscoda C. Salivary gland application of botulinum toxin for the treatment of sialorrhea. Med Oral Patol Oral Cir Bucal. 2007;12:511-7.

14. Alonso-Navarro H, Jiménez-Jiménez FJ, Plaza-Nieto JF ve ark. Treatment of severe bruxism with botulinum toxin type A. RevNeurol. 2011;53:73-6.

15. Fernández-Núñez T, Amghar-Maach S, Gay-Escoda C. Efficacy of botulinum toxin in thetreatment of bruxism: Systematic review. Med Oral Patol Oral Cir Bucal. 2019;24(4):416-24.

16. Kumar A, Spivakovsky S. Bruxism- is botulinum toxin an effective treatment? Evid Based Dent. 2018;19(2):59.

17. Dursun R, Tanır S. Botulinum toksininin kozmetik uygulamaları. Ertam Sağduyu İ, editör. Her Yönüyle Botulinum Toksin Uygulamalarına Yeniden Bakış. 1. Bask1. Ankara: Türkiye Klinikleri; 2019. p.14-30.

18. Rohrbach S, Laskawi R. Praktische Anwendungvon Botulinumtoxin im Kopf-Hals-Bereich [Botulinumtoxin in otorhinolaryngology]. HNO. 2004;52(7):635-41.

19. Pirazzini M, Rossetto O, Eleopra R, Montecucco C. Botulinum Neurotoxins: Biology, Pharmacology, and Toxicology. Pharmacol Rev. 2017;69(2):200-35.

20. Rosow DE, Pechman A, Saint-Victor S ve ark. Factors influencing botulinum toxin dose instability in spasmodicdysphonia patients. J Voice. 2015;29(3):352-5.

21. Goldenberg M, DanovitchI, IsHak WW. Quality of life andsmoking. Am J Addict. 2014;23(6):540-62 